\title{
Quality of life and hospital re-admission in patients with chronic obstructive pulmonary disease
}

\author{
L M Osman, D J Godden, J A R Friend, J S Legge, J G Douglas
}

\begin{abstract}
Background - There is some evidence that quality of life (QOL) in patients with chronic obstructive pulmonary disease (COPD) may predict clinical outcomes and use of resources. This study examined whether QOL scores could prospectively predict re-admission for COPD or death within 12 months of an original admission, and whether QOL scores predicted home nebuliser provision.

Methods - The study was carried out in all acute medical wards of Aberdeen Royal Infirmary, Woodend and City Hospitals, Aberdeen over 12 months. A total of 377 patients admitted with an exacerbation of COPD were identified in this time, 111 of whom were not included in the study because they refused the interview or died before discharge. The remaining 266 patients completed the St George's Respiratory Questionnaire (SGRQ). Information on spirometric parameters, nebuliser provision at discharge, provision of domiciliary oxygen, and re-admission within 12 months was collected from patient notes.
\end{abstract}

Results - The mean age of the patients was 68 years and $53 \%$ were men. The mean (SD) forced expiratory volume in one second $\left(\mathrm{FEV}_{1}\right)$ was $38.8(\mathbf{1 8 . 0}) \%$ predicted and forced vital capacity (FVC) was 58.9 (23.8)\% predicted. Higher (worse) scores on the SGRQ were significantly related to re-admission for COPD in the next 12 months (difference $=4.8,95 \%$ CI 1.6 to 8.0). Patients who were re-admitted and died from COPD did not differ in SGRQ scores from those who were re-admitted and survived for more than 12 months. Re-admission was not related to sex, age, or pulmonary function. One hundred and thirty eight patients did not have a home nebuliser before admission. Of these, 14 were provided with a home nebuliser at discharge. Patients provided with nebulisers had significantly worse SGRQ scores and worse FVC. The 41 patients given domiciliary oxygen did not differ in SGRQ or spirometric parameters. Logistic regression analysis of the three SGRQ subscales (Symptom, Impact and Activity), adjusting for lung function, age and sex, showed that all three subscales were significantly related to hospital readmission and that Impact scores were related to nebuliser provision. Women did not differ from men in Symptom scores on the SGRQ but differed markedly on the Activity and Impact scales.

Conclusions - It is concluded that poor scores on the SGRQ, a QOL scale which measures patient distress and coping, are associated with re-admission for COPD and use of resources such as nebulisers, independent of physiological measures of disease severity.

(Thorax 1997;52:67-71)

Keywords: chronic obstructive pulmonary disease, hospital admission, quality of life.

Quality of life (QOL) scales assess the impact of illness and experience of health among individuals. These scales include general "well being" measures such as the Sickness Impact Profile (SIP) ${ }^{1}$ and the General Health Survey $(\mathrm{SF}-36)^{2}$ and measures especially designed for respiratory disease such as the Chronic Respiratory Questionnaire $(\mathrm{CRQ})^{3}$ and the St George's Respiratory Questionnaire (SGRQ). ${ }^{4}$ Respiratory QOL measures focus on the patient's experience of symptoms, how far symptoms such as breathlessness limit daily life activity, and how much distress the disease causes the patient. ${ }^{56}$ Jones et $a l^{7}$ argue that QOL measures are particularly relevant to the management of patients with chronic obstructive pulmonary disease (COPD) because much of this care is palliative and directed to improving patients' experience of health and well being.

Studies have found that QOL of patients with COPD improves after intervention such as taking part in pulmonary rehabilitation programmes. ${ }^{8-10}$ However, improvement in QOL does not correlate very strongly with changes in physiological indicators. ${ }^{61112}$ The relation of QOL to improvement in exercise tolerance has varied in different studies. Wijkstra found that, while both QOL and exercise tolerance improved after rehabilitation, the improvements were not correlated. ${ }^{13}$ These weak relationships between QOL and physiological measures raise the question of whether QOL scores have real clinical significance. However, Traver ${ }^{14}$ found that, among patients with severe COPD, those who used more acute services had significantly higher (worse) SIP scores although assessed symptom severity did not differ, and $\mathrm{Siu}^{15}$ found that the SF-20 predicted admission to hospital in elderly patients. Cox et $a l^{16}$ carried out a randomised trial of a three month rehabilitation 
Table 1 Target population: all patients admitted over 12 months to Aberdeen hospitals with a diagnosis of COPD

St George's interview Refused interview

Not interviewed (deaf or confused)

Died during admission

tirst 48 hours of admission

Total

Table 2 St George's Respiratory Questionnaire (SGRQ) descriptive statistics $(n=266)$

\begin{tabular}{lllll}
\hline & Mean & Median & SD & Range \\
\hline Total SGRQ & 52.7 & 53.4 & 13.1 & $10.9-80.5$ \\
SGRQ Symptoms & 78.0 & 80.2 & 14.7 & $24.0-100.0$ \\
SGRQ Impact & 43.7 & 43.7 & 16.5 & $0-84.3$ \\
SGRQ Activity & 54.4 & 57.1 & 13.6 & $0-81.5$ \\
\hline
\end{tabular}

programme for 88 patients with COPD and asthma, all of whom seemed to show excessive impairment for their level of pulmonary function in terms of hospital admissions and days of inactivity. He followed these patients for two years and found that initial improvement in pulmonary function in the intervention group was not maintained in the long term, but improvement in "experienced invalidity" was maintained over two years with an accompanying significant reduction in days in hospital for the intervention patients.

From these studies it appears that poor QOL may be related to a greater likelihood of admission to hospital. If QOL is related to risk of hospitalisation, then bringing about change in QOL, even without associated physiological change, may have important consequences for effective use of resources. Ketelaars et $a l^{12}$ have recently shown that scores on the SGRQ are related to "coping strategies" of patients with COPD, with those who use a coping strategy of avoidance or denial having better QOL scores.

As part of an audit of inpatient care of patients with chronic respiratory disease we decided to included a QOL measure which would allow us to test whether those patients who had worse QOL were at greater risk of being admitted again in the next 12 months. Nebuliser provision is also likely to reflect the impact of illness on daily activities and distress of patients, so we decided to investigate whether this related to patient QOL. Review of the literature suggested that the SGRQ was a validated QOL measure which would be easy to administer and score. We therefore carried out a study to see if scores on this QOL measure would be associated with clinical outcomes and use of resources.

Table 3 Outcomes over 12 months and total SGRQ score $(n=266)$

\begin{tabular}{lrrrlll}
\hline & \multicolumn{2}{c}{ Study group } & & \multicolumn{2}{l}{ Total SGRQ scores } \\
\cline { 2 - 3 } \cline { 6 - 7 } & No. & $\%$ & & Mean $(S D)$ & Range \\
\hline No further admission (survived) & 129 & 49 & & $51.4(12.9)$ & $10.9-75.7$ \\
COPD admission (survived) & 92 & 35 & & $56.4(12.1)$ & $23.5-80.5$ \\
COPD death & 17 & 6 & & $55.3(9.6)$ & $36.5-74.6$ \\
Death, not re-admitted or not COPD & 23 & 9 & & $46.2(13.3)$ & $13.3-70.0$ \\
No records at follow up & 5 & 2 & & $37.2(21.8)$ & $15.9-71.1$ \\
\hline
\end{tabular}

\section{Methods}

The study was carried out during a 12 month audit (March 1991 to February 1992) of care of patients admitted with an exacerbation of COPD to any acute medical ward of hospitals in Aberdeen. Two respiratory nurses identified patients with COPD by contacting wards (in the respiratory unit and eight non-respiratory units) after their receiving days. From hospital computer records 478 patients had a primary discharge diagnosis of COPD during the study, of whom 101 were not identified during the first 48 hours of their hospital stay and not approached for interview. They did not differ from those studied in pulmonary function, age, or outcome over the following 12 months. The remaining $377(79 \%)$ patients were identified for the study during their stay in hospital, 266 of whom completed the SGRQ (61 patients refused the interview, 12 were unable to be interviewed because of deafness (7) or confusion (5), and 38 patients died during their admission and were excluded from the analysis; table 1). This non-interviewed group also did not differ from those studied in pulmonary function, age, or outcome over the following 12 months. Data were collected from patient notes on spirometric indices, provision of nebuliser and domiciliary oxygen before admission and at discharge, and follow up after discharge. After one year all case records were re-examined for re-admissions and deaths.

The SGRQ contains 76 items which ask patients to review the past 12 months for frequency of respiratory symptoms, impact or distress caused to them by symptoms, and limitations of activity because of symptoms. Answers to SGRQ items are weighted and total SGRQ score and scores on the three subscales (Symptom frequency, Impact, and Activity) are calculated by adding these weights. ${ }^{17}$ Scores are then converted to percentages by dividing the weighted score obtained by the total possible weighted score. The higher the score the poorer the quality of life. A difference of $4 \%$ is taken to be clinically significant on the total or subscales. ${ }^{17}$ The results of the SGRQ were not made known to doctors during the study.

Statistical analysis was carried out using SPSS-PC. SGRQ scores were normally distributed and $t$ tests were used to compare group means. Spearman correlation coefficients were calculated. Logistic regression was used to establish odds ratios for re-admission and nebuliser provision, adjusting for age, sex, and lung function (where patients did not have spirometric results mean substitution was used).

\section{Results}

The mean (SD) age of the 266 patients was 68 (9.1) years (range 44-92); 141 (53\%) were men. There were 50 current smokers $(19 \%)$, 194 former smokers $(73 \%), 20(8 \%)$ had never smoked, and for two patients this item was not answered. One hundred and eighteen patients $(44 \%)$ were in the care of respiratory medicine consultants during their initial hospital admission and 148 in the care of consultants in 
Table 4 Mean SGRQ scores and pulmonary function by re-admission and survival status, provision of nebuliser, and provision of domiciliary oxygen $(n=238)$

\begin{tabular}{|c|c|c|c|c|c|}
\hline & $\begin{array}{l}\text { No further COPD } \\
\text { admission and } \\
\text { survived }(n=129)\end{array}$ & $\begin{array}{l}\text { Further COPD } \\
\text { admission or death } \\
(n=109)\end{array}$ & Difference & $95 \% C I$ & $p$ value \\
\hline Total SGRQ & 51.4 & 56.2 & 4.8 & 1.6 to 8.0 & 0.003 \\
\hline SGRQ Symptoms & 76.4 & 81.3 & 4.9 & 1.2 to 8.5 & 0.009 \\
\hline SGRQ Impact & 42.4 & 48.0 & 5.6 & 1.6 to 9.6 & 0.004 \\
\hline SGRQ Activity & 53.6 & 56.9 & 3.3 & 0.2 to 6.9 & 0.04 \\
\hline $\mathrm{FEV}_{1}(\%$ pred $)(\mathrm{n}=168)$ & 39.4 & 38.2 & 1.2 & -4.3 to 6.7 & 0.7 \\
\hline FVC ( $\%$ pred $)(\mathrm{n}=157)$ & 58.6 & 59.2 & 0.6 & -8.2 to 6.8 & 0.9 \\
\hline No nebuliser on admission $(n=138)$ & $\begin{array}{l}\text { No nebuliser at } \\
\text { discharge }(n=124)\end{array}$ & $\begin{array}{l}\text { Nebuliser at discharge } \\
(n=14)\end{array}$ & & & \\
\hline Total SGRQ & 50.2 & 60.1 & 9.9 & 2.6 to 17.2 & 0.001 \\
\hline SGRQ Symptoms & 76.3 & 82.8 & 6.5 & -1.6 to 14.7 & 0.10 \\
\hline SGRQ Impact & 40.8 & 52.8 & 12.0 & 3.0 to 21.0 & 0.01 \\
\hline SGRQ Activity & 52.4 & 60.7 & 8.3 & 0.8 to 16.6 & 0.05 \\
\hline $\mathrm{FEV}_{1}(\%$ pred $)(\mathrm{n}=98)$ & 41.0 & 37.0 & 4.0 & -8.5 to 16.5 & 0.5 \\
\hline \multirow[t]{2}{*}{ FVC $(\%$ pred $)(n=92)$} & 63.8 & 45.9 & 17.9 & 3.3 to 32.5 & 0.02 \\
\hline & $\begin{array}{l}\text { No domiciliary } \mathrm{O}_{2} \\
(n=197)\end{array}$ & $\begin{array}{l}\text { Domiciliary } \mathrm{O}_{2} \\
(n=41)\end{array}$ & & & \\
\hline Total SGRQ & 53.5 & 54.0 & 1.5 & -4.9 to 4.0 & 0.8 \\
\hline SGRQ Symptoms & 78.9 & 77.1 & 1.8 & -6.9 to 3.1 & 0.4 \\
\hline SGRQ Impact & 44.6 & 45.6 & 1.0 & -6.7 to 4.5 & 0.4 \\
\hline SGRQ Activity & 55.3 & 54.3 & 1.0 & -3.7 to 6.5 & 0.6 \\
\hline $\mathrm{FEV}_{1}(\%$ pred $)(\mathrm{n}=168)$ & 39.2 & 37.1 & 2.14 & -5.1 to 9.4 & 0.6 \\
\hline FVC $(\%$ pred $)(n=157)$ & 60.1 & 53.4 & 6.7 & -1.4 to 14.9 & 0.10 \\
\hline
\end{tabular}

$\mathrm{FEV}_{1}=$ forced expiratory volume in one second; $\mathrm{FVC}=$ forced vital capacity.

other specialities. Spirometric tests were performed by 168 patients, mainly those in the care of respiratory specialists. The mean (SD) forced expiratory volume in one second $\left(\mathrm{FEV}_{1}\right)$ was $38.8(18.0) \%$ predicted and forced vital capacity (FVC) was 58.9 (23.8)\% predicted. The mean (SD) SGRQ score was 52.7 (13.1), range 10.9-80.5 (table 2).

Seventeen patients were admitted to hospital and died from COPD in the 12 months following the audit. There was no significant difference in SGRQ score between these patients and those re-admitted for COPD who survived for 12 months (difference $=1.1,95 \%$ $\mathrm{CI}-5.0$ to $7.3, \mathrm{p}=0.7$ ). These 17 deaths from COPD were grouped with the 92 COPD readmissions as "re-admitted for COPD or COPD death in 12 months". Another 23 patients either died from non-COPD causes (five cardiac failure, three carcinomas, one gastrointestinal haemorrhage) or died without a hospital re-admission in the following 12 months and with no stated cause of death in their notes. These patients had a better score on the SGRQ than all other groups (difference $=7.4,95 \%$ CI 1.5 to $13.4, p=0.01)$. For

Table 5 Correlations between SGRQ scores, lung function, and age

\begin{tabular}{lcccc}
\hline & $\begin{array}{l}\text { SGRQ } \\
\text { Total }\end{array}$ & $\begin{array}{l}\text { SGRQ } \\
\text { Symptoms }\end{array}$ & $\begin{array}{l}\text { SGRQ } \\
\text { Impact }\end{array}$ & $\begin{array}{r}\text { SGRQ } \\
\text { Activity }\end{array}$ \\
\hline $\mathrm{FEV}_{1}$ (\% pred) & 0.07 & -0.00 & 0.09 & 0.03 \\
$\mathrm{FVC}$ (\% pred) & 0.01 & -0.04 & 0.04 & -0.12 \\
Age & $-0.17^{* *}$ & -0.10 & $-0.19^{* *}$ & -0.07 \\
\hline $\mathrm{FEV}_{1}=$ forced expiratory volume in one second; FVC $=$ forced \\
vital capacity. \\
$* * \mathrm{p}<0.01$.
\end{tabular}

Table 6 Relationship between SGRQ scores and sex

\begin{tabular}{llllrl}
\hline & $\begin{array}{l}\text { Men } \\
(n=123)\end{array}$ & $\begin{array}{l}\text { Women } \\
(n=115)\end{array}$ & Difference & 95\% CI & p value \\
\hline Total SGRQ & 51.1 & 56.2 & 5.1 & 1.9 to 8.2 & 0.001 \\
SGRQ Symptoms & 77.7 & 79.7 & 2.0 & -5.7 to 1.6 & 0.28 \\
SGRQ Impact & 42.1 & 47.9 & 5.8 & 1.7 to 9.7 & 0.005 \\
SGRQ Activity & 52.1 & 58.3 & 6.2 & 2.9 to 9.9 & 0.001 \\
\hline
\end{tabular}

this reason they were excluded from further analysis. For five patients the notes could not be found at follow up, leaving 238 patients in the final analysis (table 3 ).

Table 4 shows differences in total SGRQ scores and scores for the three subscales between those re-admitted (and/or died from COPD related causes) and those not re-admitted. Both the total SGRQ score and the subscale scores were significantly different between the two groups, with differences ranging from 3.3 to 5.6. The largest difference (5.6) was in the Impact subscale which measures the distress caused to patients by their condition. Neither FEV 1 nor FVC distinguished between re-admissions and those not readmitted. Age, sex, and current smoking status did not relate to risk of re-admission.

One hundred patients (42\%) had home nebulisers before coming into hospital and continued with their use after returning home. These patients had significantly worse SGRQ scores (56.9 versus $51.2,95 \%$ CI 2.5 to 8.8 ). Of the 138 patients without a nebuliser on entry, 14 were prescribed a nebuliser at discharge. Provision of a home nebuliser at discharge was significantly related to total SGRQ score $(\mathrm{p}<0.001)$ and to the Impact and Activity subscales (table 4). Nebuliser provision was significantly related to spirometric results (FVC, $\mathrm{p}=0.01$ ). Age, sex, and current smoking status did not relate to nebuliser provision.

Forty one patients had domiciliary oxygen, the use of which did not relate to SGRQ score or spirometric results. Examination of the SGRQ subscales showed that symptoms did not vary with age but QOL impact was significantly greater for younger patients (table 5). Women also reported more impact and restriction of activity than men without reporting significantly more symptoms (table 6).

Logistic regression analysis was used to establish odds ratios for the relation between SGRQ subscales and re-admission and nebuliser provision. Odds ratios were adjusted 
Table 7 Estimated odds ratios for re-admission or nebuliser provision on the subscales of the $S G R Q$

\begin{tabular}{lll}
\hline SGRQ subscale* & \multicolumn{2}{l}{ Re-admission within 12 months $(n=238)$} \\
\cline { 2 - 3 } & $\begin{array}{l}\text { Unadjusted } \text { OR } \\
(95 \% \text { CI })\end{array}$ & $\begin{array}{l}\text { Adjusted } O R \\
(95 \% C I)^{13}\end{array}$ \\
\hline Symptoms & $1.13(1.03$ to 1.25$)$ & $1.14(1.04$ to 1.26$)$ \\
Impact & $1.12(1.03$ to 1.22$)$ & $1.14(1.05$ to 1.25$)$ \\
Activity & $1.10(0.99$ to 1.23$)$ & $1.13(1.01$ to 1.25$)$
\end{tabular}

Nebuliser provision at discharge among patients without nebuliser on entry $(n=138)$

Unadjusted $O R \quad$ Adjusted $O R$

$\begin{array}{ll}(95 \% \mathrm{CI}) & (95 \% \mathrm{CI})^{23}\end{array}$

$1.19(0.95$ to 1.50$) \quad 1.21(0.95$ to 1.54$)$

$\begin{array}{llll}\text { Symptoms } & 1.25(1.04 \text { to } 1.51) & 1.25(1.03 \text { to } 1.51) \\ \text { Impact } & 1.30(0.99 \text { to } 1.70) & 1.35(0.99 \text { to } 1.83) \\ \text { Activity } & & \end{array}$

Activity $1.30(0.99$ to 1.70$)$

(0.99 to 1.83$)$

* Odds ratios show the effect of a five point change on each scale.

${ }^{1}$ Adjusted for age, \% predicted $\mathrm{FEV}_{1}$ and FVC, sex, and nebuliser provision (at discharge and before entry to hospital) ${ }^{2}$ Adjusted for age, $\%$ predicted $\mathrm{FEV}_{1}$ and $\mathrm{FVC}$, and sex.

${ }_{3}^{3}$ Mean substitution was used for the 70 cases where no spirometric data were available.

for effects of age, sex, and lung function. For adjusted odds ratios, Symptoms, Impact and Activity were all significantly related to readmission and Impact was also related to nebuliser provision (table 7 ).

Over the 12 months following the audit 55\% of patients with nebulisers were re-admitted compared with $45 \%$ of patients without nebulisers $(p<0.01)$. This difference was no longer significant when SGRQ score was controlled for in a logistic regression analysis.

Patients in the care of respiratory physicians did not differ in Symptom QOL but had worse Impact QOL (difference $=4.4, \mathrm{p}=0.03$ ) and worse Activity QOL (difference $=3.2, \mathrm{p}=0.05$ ) and were more likely to be re-admitted $(53 \%$ versus $40 \%, \mathrm{p}<0.05)$.

\section{Discussion}

These results show that patients with poor QOL are at greater risk of hospital re-admission after an initial admission and that patients are also more likely to be provided with home nebulisers if they have poor QOL. The results also suggest that patients are likely to be referred to respiratory specialists if they have poor QOL. We did not find that percentage predicted $\mathrm{FEV}_{1}$ or FVC was related to readmission within 12 months among this group of patients. The results of this study suggest that, in patients whose range of lung function is restricted, differences in QOL are more significantly related to clinical decisions and use of resources than are differences in pulmonary function.

QOL scales are designed to measure psychological impact and subjective experience of patients, but all QOL scales also have a symptom component. It might be the symptom measure component of the total score which predicts risk of admission to hospital rather than the more subjective components measuring distress and daily life limitation. Because the SGRQ provides separate subscale scores for Symptoms, Impact and Activity we were able to test which aspects of QOL best discriminated differences in outcome between patients. Although all scales showed differences between patients, the Impact subscale showed the largest differences in re-admission to hospital and nebuliser provision. Among this group of patients with COPD, all of whom had quite high symptom scores, those with greater distress and poorer coping were more likely to be re-admitted and provided with nebulisers. This was so, even though the patients were under the care of a large number of consultants in both respiratory medicine and other specialities.

Activity limitation as assessed by the Activity subscale of the SGRQ subscale was relatively poorly related to re-admission to hospital or nebuliser provision. The Activity scores did show that significant differences in self perceived activity limitation exist between men and women and older and younger patients. Women with COPD feel they are more limited in activities than do men, and women experience greater distress from their illness without reporting any worse levels of symptoms. The patients who were relatively younger also showed most signs of suffering from the psychological impact of their disease. The greater distress caused by COPD to these groups has been previously reported. ${ }^{18}$

Patients with a home nebuliser were more likely to be re-admitted to hospital over the following 12 months but when we controlled for SGRQ score the relationship between nebuliser and re-admission was no longer significant, showing that the greater number of admissions among patients with a home nebuliser was unlikely to be due to the provision of a nebuliser per se. This illustrates how a valid QOL measure can be used to correct for differences between patients when investigating differences in outcome.

Assessing patient coping and the impact of disease on patients is a normal part of the clinical interview and it is not surprising that poor quality of life should be related to decisions to admit to hospital or to provide support such as home nebulisers. QOL measures can reflect this clinical assessment, but at present such scales do not have great enough sensitivity to be used as determinants of clinical decisions. Guyatt, however, found that patients were more reluctant to volunteer information about the emotional impact of illness ${ }^{19}$ than about symptoms, and he has suggested that QOL scales should provide a way of eliciting areas of distress for patients.

Poor QOL in patients with COPD has previously been linked to greater use of health resources ${ }^{14}$ and the study by Cox et $a l^{16}$ suggests that, when QOL improves, even though lung function does not, consultations and hospital admissions decrease. The results of our study are compatible with those of Cox et al in showing that poor QOL is associated with a greater chance of admission and of nebuliser provision. Thus QOL outcomes, even when there is no physiological improvement, may be important in assessing the success of interventions in patients with COPD. The SGRQ appears to distinguish patients who cope relatively well, despite having high symptom levels, and to show that this good coping has clinical con- 
sequences. This therefore offers the possibility of using QOL scales to identify patients who cope poorly and directing interventions to them.

Ketelaars et $a l^{12}$ have recently shown the complex relationship that exists between the subscales of the SGRQ and measures of coping and physical performance. They have commented that "longitudinal studies are needed to disentangle the cause and effect relationships suggested by (their) findings". The present study shows that, in a longitudinal study, QOL is associated with hospital admission in patients with moderate to severe limitations in lung function. We do not yet know how strongly QOL would predict hospital admission among a milder group of patients, but the studies previously described suggest that poor QOL plays a part in increasing risk of hospitalisation at all levels of physiological impairment. We conclude that the results of this study suggest an important area of research into patient experience of COPD and its impact on clinical decision making and the use of resources.

The National Asthma Campaign Senior Research Fellowship of LMO is funded by the Astra Foundation.

1 Bergner M, Bobbitt RA, Carter WB, Gilson BS. The Sickness Impact Profile: development and final revision of a health status measure. Med Care 1981;19:787-805.

2 Stewart AL, Hays RD, Ware JE Jr. The MOS short-form general health survey. Reliability and validity in a patient population. Med Care 1988;26:724-35.

3 Guyatt GH, Berman LB, Townsend M, Pugsley SO, Chambers LW. A measure of quality of life for clinical trials in chronic lung disease. Thorax 1987;42:773-8.

4 Jones PW, Quirk FH, Baveystock CM, Littlejohns P. A selfcomplete measure of health status for chronic airflow limitation. The St George's Respiratory Questionnaire. Am Rev Respir Dis 1992;145:1321-7.

5 Juniper EF, Guyatt GH, Ferrie PJ, Griffith LE. Measuring quality of life in asthma. Am Rev Respir Dis 1993;147 832-8.

6 Schrier AC, Dekker FW, Kaptein AA, Dijkman JH. Quality of life in elderly patients with chronic nonspecific lung disease seen in family practice. Chest 1990;98:894-9.

7 Jones PW, Quirk FH, Baveystock CM. Why quality of life measures should be used in the treatment of patients with respiratory illness. Monaldi Arch Chest Dis 1994;49:79-82.

8 Toshima MT, Kaplan RM, Ries AL. Experimental evaluation of rehabilitation in chronic obstructive pulmonary disease: short-term effects on exercise endurance and health status. Health Psychol 1990;9:237-52.

9 Emery CF, Leatherman NE, Burker EJ, MacIntyre NR. Psychological outcomes of a pulmonary rehabilitation program. Chest 1991;100:613-7.

10 Goldstein RS, Gort EH, Stubbing D, Avendano MA, Guyat $\mathrm{GH}$. Randomised controlled trial of respiratory rehabilitation. Lancet 1994;344:1394-7.

11 Wiikstra PJ, TenVergert EM, van der Mark TW, et al. Relation of lung function, maximal inspiratory pressure, dyspnoea, and quality of life with exercise capacity in dyspnoea, and quality of life with exercise capacity in Thorax 1994;49:468-72.

12 Ketelaars CAJ, Schlosser MAG, Mostert R, Huyer AbuSaad H, Halfens RJG, Wouters EFM. Determinants of health related quality of life in patients with chronic obstructive pulmonary disease. Thorax 1996;51:39-43.

13 Wijkstra PJ, Van Altena R, Kraan J, Otten V, Postma DS, Koeter GH. Quality of life in patients with chronic obstructive pulmonary disease improves after rehabilitation at home. Eur Respir f 1994;7:269-73

14 Traver GA. Measures of symptoms and life quality to predict emergent use of institutional health care resources in chronic obstructive airways disease. Heart Lung 1988;17: 689-97.

15 Siu AL, Reuben DB, Ouslander JG, Osterweil D. Using multidimensional health measures in older persons to identify risk of hospitalization and skilled nursing placement. Quality of Life Res 1993;2:253-61.

16 Cox NJ, Hendricks JC, Binkhorst RA, van Herwaarden CL A pulmonary rehabilitation program for patients with asthma and mild chronic obstructive pulmonary diseases (COPD). Lung 1993;171:235-44.

17 Jones P, Quirk FH, Baveystock CM. The St George's Respiratory Questionnaire. Respir Med 1991;85:25-31.

18 Kinsman RA, Yaroush RA, Fernandez E, Dirks JF, Schocket M, Fukuhara J. Symptoms and experiences in chronic bronchitis and emphysema. Chest 1983;83:755-61.

19 Guyatt GH, Townsend M, Berman LB, Pugsley SO. Quality of life in patients with chronic airflow limitation. $B r \mathcal{F} D i$ Chest 1987;81:45-54. 